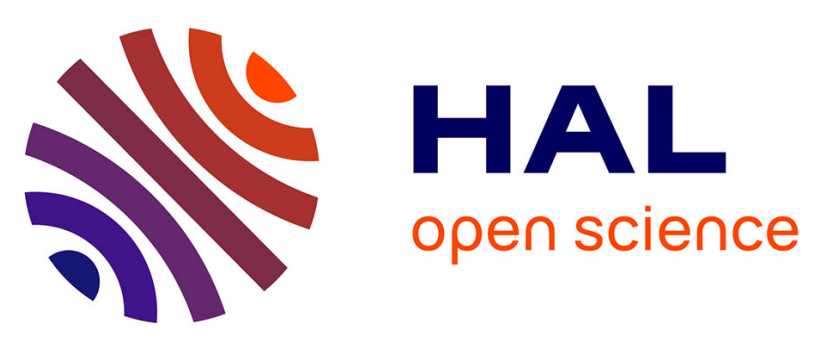

\title{
What Stator Current Processing Based Technique to Use for Induction Motor Rotor Faults Diagnosis?
}

Mohamed Benbouzid, Gerald Kliman

\section{To cite this version:}

Mohamed Benbouzid, Gerald Kliman. What Stator Current Processing Based Technique to Use for Induction Motor Rotor Faults Diagnosis?. IEEE Transactions on Energy Conversion, 2003, 18 (2), pp.238-244. hal-01052444

\section{HAL Id: hal-01052444 \\ https://hal.science/hal-01052444}

Submitted on 26 Jul 2014

HAL is a multi-disciplinary open access archive for the deposit and dissemination of scientific research documents, whether they are published or not. The documents may come from teaching and research institutions in France or abroad, or from public or private research centers.
L'archive ouverte pluridisciplinaire $\mathbf{H A L}$, est destinée au dépôt et à la diffusion de documents scientifiques de niveau recherche, publiés ou non, émanant des établissements d'enseignement et de recherche français ou étrangers, des laboratoires publics ou privés. 


\title{
What Stator Current Processing Based Technique to Use for Induction Motor Rotor Faults Diagnosis?
}

\author{
Mohamed Benbouzid, Senior Member, IEEE and Gerald B. Kliman, Life Fellow, IEEE
}

\begin{abstract}
In recent years, marked improvement has been achieved in the design and manufacture of stator winding. However, motors driven by solid-state inverters undergo severe voltage stresses due to rapid switch-on and switch-off of semiconductor switches. Also, induction motors are required to operate in highly corrosive and dusty environments. Requirements such as these have spurred the development of vastly improved insulation material and treatment processes. But cage rotor design has undergone little change. As a result, rotor failures now account for a larger percentage of total induction motor failures. Broken cage bars and bearing deterioration are now the main cause of rotor failures. Moreover, with advances in digital technology over the last years, adequate data processing capability is now available on cost-effective hardware platforms, to monitor motors for a variety of abnormalities on a real time basis in addition to the normal motor protection functions. Such multifunction monitors are now starting to displace the multiplicity of electromechanical devices commonly applied for many years. For such reasons, this paper is devoted to a comparison of signal processing based techniques for the detection of broken bars and bearing deterioration in induction motors. Features of these techniques which are relevant to fault detection are presented. These features are then analyzed and compared to deduce the most appropriate technique for induction motor rotor fault detection.
\end{abstract}

Index Terms - Induction motor, rotor fault diagnosis, stator current.

\section{INTRODUCTION}

It is well known that induction motors dominate the field of electromechanical energy conversion. These machines find a wide role in most industries in particular in the electric utility industry as auxiliary drives in central power plants of power systems, as well as restricted role in low MVA power supply systems as induction generators, mining industries, petrochemical industries, as well as in aerospace and military equipment. Therefore, assessments of the running conditions and reliability of these drive systems is crucial to avoid unexpected and catastrophic failures. Consequently, the issue of preventive maintenance and noninvasive diagnosis of the condition of these induction motors drives is of great concern, and is becoming increasingly important [1-2].

M.E.H. Benbouzid is with the Centre de Robotique, d'Electrotechnique et d'Automatique (CREA) of the University of Picardie - Jules Verne at Amiens, 7, Rue du Moulin Neuf, 80000 Amiens, France (e-mail: m.benbouzid@ieee.org).

G.B. Kliman is with the Electrical, Computer \& Systems Engineering Department, Rensselaer Polytechnic Institute, Troy, NY 12180-3590 USA (klimag@rpi.edu)
In recent years, marked improvement has been achieved in the design and manufacture of stator winding. However, motors driven by solid-state inverters undergo severe voltage stresses due to rapid switch-on and switch-off of semiconductor switches. Also, induction motors are required to operate in highly corrosive and dusty environments. Requirements such as these have spurred the development of vastly improved insulation material and treatment processes. But cage rotor design has undergone little change [3]. As a result, rotor failures now account for a larger percentage of total induction motor failures (Fig. 1) [4]. Broken cage bars and bearing deterioration are now the main cause of rotor failures (Fig. 2).

In general, condition-monitoring schemes have concentrated on sensing specific failures modes in one of three induction motor components: the stator, the rotor, or the bearings. Even though thermal and vibration monitoring have been utilized for decades, most of the recent research has been directed toward electrical monitoring of the motor with emphasis on inspecting the stator current of the motor [5].

Fault detection based on motor current relies on interpretation of the frequency components in the current spectrum that are related to rotor or bearing asymmetries. However, the current spectrum is influenced by many factors, including electric supply, static and dynamic load conditions, noise, motor geometry, and fault conditions. These conditions may lead to errors in fault detection.

With advances in digital technology in recent years, adequate data processing capability is now available on costeffective hardware platforms, to monitor motors for a variety of abnormalities on a real time basis in addition to the normal motor protection functions. Such multifunction monitors are now starting to displace the multiplicity of electromechanical devices commonly applied for many years. For such reasons, this paper is devoted to a comparison of signal processing based techniques for the detection of broken bars and bearing deterioration in induction motors. Features of these techniques which are relevant to fault detection are presented. These features are then analyzed and compared to deduce the most appropriate technique for induction motor rotor fault detection.

\section{MOTOR CURRENT SPECTRAL COMPONENTS}

\section{A. Broken Bars}

The broken rotor bar frequencies in the motor current are given by [6] 


$$
f_{b r b}=f_{s}\left[k\left(\frac{1-s}{p}\right) \pm s\right]
$$

Where $f_{s}$ is the electrical supply frequency, $k / p=1,5,7,11$, $13, \cdots$ (due to the normal winding configuration), $s$ is the per unit slip, and $p$ is the number of pole pairs.

Even though the predicted frequencies are the same for both airgap dynamic eccentricity [5] and broken bars, the sideband amplitudes corresponding to a particular harmonic number are different allowing the two faults to be distinguished. The amplitude of the sideband frequency component is roughly proportional to the number of broken rotor bars. In fact, the amplitude $I_{b r b}$ of frequency component $f_{s}(1-2 s)$ can be approximated by [7]

$$
\frac{I_{b r b}}{I_{s}} \cong \frac{\sin \alpha}{2 p(2 \pi-\alpha)}
$$

Where $I_{s}$ is the stator current fundamental frequency component,

$$
\alpha=\frac{2 \pi R_{b} p}{R}
$$

$R_{b}$ is the number of broken bars.

By analyzing the stator current, it is possible to evaluate the general condition of the rotor. If there are broken bars in various parts of the rotor, the current analysis is not capable of providing information on the configuration of noncontiguous broken bars. For example, the frequency component $f_{s}(1-2 s)$ does not exist if broken bars are electrically $\pi / 2$ radians away from each other. It should be noted that some experimental studies have demonstrated that both skewing and noninsulation of rotor bars lead to reduce the broken rotor bar harmonic components. It has been demonstrated experimentally that when the amplitude of these harmonics is over $50 \mathrm{~dB}$ smaller than the fundamental frequency component amplitude, the rotor may be considered healthy [7].

\section{B. Bearings Fault}

Bearing problems are often caused by improperly forcing the bearing onto the shaft or into the housing. This produces physical damage in the form of brinelling or false brinelling of the raceways, which leads to premature failure. Misalignment of the bearing, which occurs in the four ways depicted in Fig. 3 , is also a common result of defective bearing installation.

The relationship of the bearing vibration to the stator current spectra can be determined by recalling that any air gap eccentricity produces anomalies in the air gap flux density. Since ball bearings support the rotor, any bearing defect will produce a radial motion between the rotor and stator of the machine. The mechanical displacement resulting from damaged bearings causes the machine airgap to vary in a manner that can be described by a combination of rotating eccentricities moving in both directions. As with the airgap eccentricity, these variations generate stator currents at frequencies given by

$f_{\text {bng }}=\left|f_{s} \pm m f_{i, o}\right|$

Where $m=1,2,3, \cdots$ and $f_{i, o}$ is one of the characteristic vibration frequencies which are based upon the bearing dimensions shown in Fig. 4.

$$
f_{i, o}=\frac{n}{2} f_{r}\left[1 \pm \frac{b d}{p d} \cos \beta\right]
$$

Where $n$ is the number of bearing balls, $f_{r}$ is the mechanical rotor speed in $\mathrm{Hz}, b d$ is the ball diameter, $p d$ is the bearing pitch diameter, and $\beta$ is the contact angle of the balls on the races [5]. It should be noted from (5) that specific information concerning the bearing construction is required to calculate the exact characteristic frequencies. However, these characteristic race frequencies can be approximated for most bearings with between six and twelve balls [8].

$\left\{\begin{array}{l}f_{o}=0.4 n f_{r} \\ f_{i}=0.6 n f_{r}\end{array}\right.$

This generalization allows for the definition of frequency bands where the bearing race frequencies are likely to show up without requiring explicit knowledge of the bearing construction.

\section{Load Effects}

If the load torque does vary with rotor position, the current will contain spectral components, which coincide with those caused by a fault condition. In an ideal machine where the stator flux linkage is purely sinusoidal, any oscillation in the load torque at a multiple of the rotational speed $m f_{r}$ will produce stator currents at frequencies of [9]

$$
f_{\text {load }}=f_{s} \pm m f_{r}=f_{s}\left[1 \pm m\left(\frac{1-s}{p}\right)\right]
$$

Where $m=1,2,3, \cdots$. Since the same frequencies are given by (2) and (3), it is clear that when the induction machine operates with a typical time-varying load, the torque oscillation results in stator currents that can obscure, and often overwhelm, those produced by the fault condition as illustrated by Fig. 5 [10]. Therefore, any stator current singlephase spectrum based fault detection scheme must rely on monitoring those spectral components, which are not affected by the load torque oscillations [10]. However, broken bars detection is still possible since the current typically contains higher order harmonics than those induced by the load. 


\section{Rotor FAULT DETECTION TECHNIQUES}

\section{A. Fast Fourier Transform (FFT)}

For this method, the stator current monitoring system is sketched in Fig. 6. Generally, not denying the diagnostic value of classical spectral analysis techniques, induction motor faults detection, via FFT-based stator current signature analysis, could be improved by decreasing the current waveform distortions as is illustrated by Figs. 7 and 8 [11]. Moreover, it is well known that motor current is a nonstationary signal, the properties of which vary with the time-varying normal operating conditions of the motor. As a result, it is difficult to differentiate fault conditions from the normal operating conditions of the motor using Fourier analysis.

\section{B. Instantaneous Power FFT}

In this case, in place of the stator current, the instantaneous power is used as a medium for motor signature analysis [12]. It was shown that the amount of information carried by the instantaneous power, which is the product of the supply voltage and the motor current, is higher than that deducible from the current alone. In fact, besides the fundamental and the two classical sideband components, the instantaneous power spectrum contains an additional component directly at the modulation frequency as shown by the following equation.

$$
\begin{aligned}
& p(t)=p_{0}(t)+\frac{M V_{L L} I_{L}}{2}\left\{\cos \left[\left(2 \omega+\omega_{o s c}\right) t-\varphi-\frac{\pi}{6}\right]\right. \\
& \left.+\cos \left[\left(2 \omega-\omega_{o s c}\right) t-\varphi-\frac{\pi}{6}\right]+2 \cos \left(\varphi+\frac{\pi}{6}\right) \cos \left(\omega_{o s c} t\right)\right\}
\end{aligned}
$$

Where $p$ is the instantaneous power, $M$ is the modulation index, $V_{L L}$ is the rms value of the line-to-line voltage, and $I_{L}$ is that of the line current, while $\omega$ and $\varphi$ denote the supply radian frequency and motor load angle, respectively, and $\omega_{\text {osc }}$ is the radian oscillation frequency.

As an illustration, Fig. 9 shows clearly the differences with Fig. 7b. In fact, all the fault harmonics are translated into the frequency band $0-100 \mathrm{~Hz}$. This constitutes a great advantage because the fault harmonics domain is well bounded. However, the power spectra are still quite noisy. Even adding filters has not brought significant improvement. Moreover, even though the power spectrum is particularly adapted to mechanical abnormality detection (worn or damaged bearing), it still has the same principal drawback as the classical motor current FFT (nonstationary signal).

\section{Bispectrum}

Bispectrum, also called third-order spectrum, derives from higher order statistics. The bispectrum is defined in terms of the two-dimensional Fourier transform of the third-order moment sequence of a process [13]. The bispectrum is periodic with a period of $2 \pi$, and preserves both magnitude and phase information. It is then capable of revealing both the amplitude and phase information of the signals. With these additional dimensions, fault detection and diagnostic processes can be enriched.

Very promising results were obtained, as illustrated by Fig. 10. In fact, experimental results indicate that the bispectrum magnitude of the dominant component, caused by the machine rotation, increased with the fault level increase. These results clearly indicate that stator current bispectrum is capable of providing adequate and essential spectral information for induction motors condition monitoring and fault detection. However, this technique is more appropriate for the detection of electrical based faults, such as stator voltage unbalance, because those faults do not have a wellidentified harmonic frequency component [11].

\section{High Resolution Spectral Analysis}

A main disadvantage of the classical spectral estimation is the impact of side lobe leakage due to the inherent windowing of finite data sets. Window weighting allows mitigation of the effects of side lobes at the expense of decreasing the spectral resolution that can be no better than the inverse of acquisition time. In order to improve the statistical stability of the spectral estimate, i.e. to minimize the estimate variance, pseudo ensemble averaging by segmenting the data was introduced at the price of further decreasing the resolution. A class of spectral techniques based on an eigenanalysis of the autocorrelation matrix has been promoted in the digital signal processing research literature [14].

As an illustration, two well known eigenanalysis-based frequency estimators have been used: MUSIC (Multiple Signal Classification) and ROOT-MUSIC for stator voltage unbalance underscoring [11]. In this case, one of the principal spectral components modified by the electric fault is the supply frequency third harmonic (i.e. $150 \mathrm{~Hz}$ ) whose amplitude increases in a significant way whatever the load. The two principal spectral components of the stator current spectrum are the first and the fifth harmonics $(50 \mathrm{~Hz}-250$ $\mathrm{Hz}$ ) for a healthy motor, and the first and third harmonics (50 $\mathrm{Hz}-150 \mathrm{~Hz}$ ) for a stator voltage unbalance. The MUSIC algorithm has been applied for each case and results are given in Fig. 11. With regard to these results, MUSIC and ROOTMUSIC methods allow keeping only the main frequencies without other spectral information. Moreover, stator current high-resolution spectral analysis used as a medium for induction motors faults detection will be useful for all faults modifying main spectral components.

\section{E. Wavelet Analysis}

Fourier analysis is very useful for many applications where the signals are stationary. The Fourier transform is however not appropriate to analyze a signal that has transitory 
characteristics such as drifts, abrupt changes and frequency trends. To overcome this problem it has been useful to analyze small sections of the signal at various times. This technique is known as Short-Time Fourier Transform (STFT) or windowing technique. The technique maps a signal into a two-dimensional function of time and frequency. The STFT represents a sort of compromise between time and frequency based views of a signal and it provides some information about both. However, we can only obtain this information with limited precision, and that precision is determined by the size of the window. The fixed size of the window is the main drawback of the STFT [15].

The wavelet transform was introduced with the idea of overcoming the difficulties mentioned above. A windowing technique with variable-size region is used to perform the signal analysis, which can be the stator current. Wavelet analysis allows the use of long time intervals where we want more precise low frequency information, and shorter regions where we want high frequency information. The ability to perform local analysis is one of the most interesting features of the wavelet transform. The advantages of using wavelet techniques for fault monitoring and diagnosis of induction motors is increasing because these techniques allow us to perform stator current signal analysis during transients. The wavelet technique can be used for a localized analysis in the time-frequency or time scale domain. It is then a powerful tool for condition monitoring and fault diagnosis.

As an illustration, Fig. 12 provides the result where STFT and the wavelet technique are combined. These results show the improvements introduced by the wavelet technique for the signal frequency monitoring [16].

\section{F. The Park's Vector Approach}

A two dimensional representation can be used for describing three-phase induction motor phenomena. A suitable one being based on the stator current Park's vector [17]. As a function of mains phase variables $\left(i_{a}, i_{b}, i_{c}\right)$ the current Park's vector components $\left(i_{d}, i_{q}\right)$ are

$$
\left\{\begin{array}{l}
i_{d}=\sqrt{\frac{2}{3}} i_{a}-\frac{1}{\sqrt{6}} i_{b}-\frac{1}{\sqrt{6}} i_{c} \\
i_{q}=\frac{1}{\sqrt{2}} i_{b}-\frac{1}{\sqrt{2}} i_{c}
\end{array}\right.
$$

Under ideal conditions, three-phase currents lead to a Park's vector with the following components

$$
\left\{\begin{array}{l}
i_{d}=\frac{\sqrt{6}}{2} i_{M} \sin \omega t \\
i_{q}=\frac{\sqrt{6}}{2} i_{M} \sin \left(\omega t-\frac{\pi}{2}\right)
\end{array}\right.
$$

Where $i_{M}$ is the supply phase current maximum value and $\omega_{s}$ is the supply frequency. Its representation is a circular pattern centered at the origin of the coordinates. This is a very simple reference figure that allows the detection of faulty conditions by monitoring the deviations of the acquired patterns as illustrated by Fig. 13. The healthy pattern differs slightly from the expected circular one, because supply voltage is generally not exactly sinusoidal.

Recently, a new implementation of the Park's vector approach has been proposed [18]. Under abnormal conditions, for example in the presence of rotor cage faults such as broken bars, (9) and (10) are no longer valid, because the induction motor supply current will contain sideband components at frequencies differing from the fundamental by the double slip frequency. These additional components at frequencies of (1 $2 s) f_{s}$ and $(1+2 s) f_{s}$ will also be present in both motor current Park's vector components $\left(i_{d}, i_{q}\right)$. In these conditions, it can be shown that the spectrum of the stator current Park's vector modulus is the sum of a dc level, generated mainly by the fundamental component of the induction motor supply current, plus two additional terms, at frequencies of $2 s f_{s}$ and $4 s f_{s}$. In this way, the spectrum of the stator current Park's vector modulus ac level is clear from any component at the fundamental supply frequency, making it more useful to detect the components directly related to the induction motor fault. This new implementation of the Park's vector approach is intended to eliminate some of the technical limitations of the conventional FFT technique. In fact, Fig. 14a shows that, in the absence of faults, the behavior of the induction motor is mostly characterized by the absence of any relevant spectral component. Moreover, results obtained by the extended Park's vector approach are more discriminating than those obtained by the traditional FFT technique (Fig. 14b).

\section{G. Adaptive Statistical Time-Frequency Method}

The motor current can be modeled as a nonstationary random signal. However, as previously mentioned, Fourier transform techniques are not sufficient to represent nonstationary signals. Moreover, the uncertainty involved in the system requires an adaptive statistical framework to address the problem in an efficient way. In recent years, advancement of statistical signal processing methods has provided efficient and optimal tools to process nonstationary signals. In particular, time-frequency and time-scale transformations provide an optimal mathematical framework for the analysis of time-varying, nonstationary signals [19].

Recently, an adaptive statistical time-frequency method to detect broken bars and bearing faults has been proposed. The key idea in this method is to transform the motor current into a time-frequency spectrum to capture the time variation of the frequency components and to analyze the spectrum statistically to distinguish fault conditions from the normal operating conditions of the motor. Since each motor has a distinct geometry, a supervised approach is adapted. In this approach, the algorithm is trained to recognize the normal 
operating conditions of the motor prior to actual fault detection [20].

Time localization of nonstationary signals is typically achieved by the STFT above discussed. Its mathematical description is given as follows for a given signal $f$

$$
F(\omega, n)=\frac{1}{\sqrt{2 \pi}} \int f(t) g\left(t-n t_{0}\right) e^{-i \omega t} d t
$$

Where $g$ is an ideal cut-off function, $g\left(t-n t_{0}\right)$ is a translate of $g, t_{0}$ is the length of the cut-off interval, and $n$ is an integer associated with the signal portion. $\omega$ is similar to the Fourier frequency.

The proposed detection method, as shown by Fig. 15, consists of four main stages: preprocessing (typical signal conditioning procedures), training (current time-frequency spectrum is computed and features relevant to fault conditions are extracted), testing, and postprocessing (testing is repeated to improve final the decision accuracy) [20].

For illustration, Fig. 16 shows a typical time-frequency spectrum for bearing fault detection [20].

\section{H. An additional Technique}

Recently [21], an interesting technique has been proposed for the detection of broken bars in induction motors. This technique is based on an open terminal test. In this case, rotor currents will then induce voltages in the stator windings. These voltages will be processed for the diagnosis of cracked or broken rotor bars.

This is a very interesting technique, since induction motors are generally supplied by nonideal sources with time harmonic voltages, voltage unbalance, etc. Moreover, the motor may operate in the saturation region. These frequent conditions will lead to some errors in the fault detection process. It appears that these effects will be removed by the open terminal test. This technique seems to be interesting for onsite rotor fault detection (before the motor utilization).

\section{CONCLUDING REMARKS}

The paper attempts to briefly present signal (mainly motor current) processing techniques for induction motor rotor fault detection (mainly broken bars and bearing deterioration). The main advantages and drawbacks of the above-presented techniques are also briefly discussed. In many cases, the conventional steady state techniques may suffice. From these discussions, it appears that, for the most difficult cases, timefrequency and time-scale transformations, such as wavelets, provide a more optimal tool for the detection and the diagnosis of faulty induction motor rotors. On the one hand they remedy the main drawbacks of motor current signal processing techniques for fault detection, i.e. nonstationarity. On the other hand these techniques exhibit some interesting application advantages, such as for coal crushers, where speed varies rapidly and for deteriorated bearings where speed and signatures may vary in an unpredictable manner.

\section{REFERENCES}

[1] O.V. Thorsen et al., "A survey of faults on induction motors in offshore oil industry, petrochemical industry, gas terminals, and oil refineries,' IEEE Trans. Industry Applications, vol. 31, n5, September-October 1995, pp. 1186-1196.

[2] M.E.H. Benbouzid, "Bibliography on induction motors faults detection and diagnosis," IEEE Trans. Energy Conversion, vol. 14, n 4 , December 1999, pp. 1065-1074.

[3] A.H. Bonnett et al., "Squirrel-cage rotor options for ac induction motors," IEEE Trans. Industry Applications, vol. 37, n 4, July-August 2001, pp. 1197-1209.

[4] A.H. Bonnett et al., "Rotor failures in squirrel cage induction motors," IEEE Trans. Industry Applications, vol. 22, n6, November-December 1986, pp. 1165-1173.

[5] M.E.H. Benbouzid, "A review of induction motors signature analysis as a medium for faults detection," IEEE Trans. Industrial Electronics, vol. 47, n5, October 2000, pp. 984-993.

[6] G.B. Kliman et al., "Methods of motor current signature analysis," Electric Machines \& Power Systems, vol. 20, n5, September 1992, pp. 463-474.

[7] R. Hirvonen, "On-line condition monitoring of defects in squirrel cage motors," Proceedings of the 1994 International Conference on Electrical Machines, Paris (France), vol. 2, pp. 267-272.

[8] R.L. Schiltz, "Forcing frequency identification of rolling element bearings," Sound \& Vibration, May 1990, pp. 16-19.

[9] R.R. Schoen et al., "Effects of time-varying loads on rotor fault detection in induction machines," IEEE Trans. Industry Applications, vol. 31, n4, July-August 1995, pp. 900-906.

[10] R.R. Schoen et al., "Evaluation and implementation of a system to eliminate arbitrary load effects in current-based monitoring of induction machines," IEEE Trans. Industry Applications, vol. 33, ${ }^{\circ} 6$, November-December 1997, pp. 1571-1577.

[11] M.E.H. Benbouzid et al., "Induction motors faults detection and localization using stator current advanced signal processing techniques," IEEE Trans. Power Electronics, vol. 14, n¹, pp. 14-22, January 1999.

[12] A.M. Trzynadlowski et al., "Diagnostics of mechanical abnormalities in induction motors using instantaneous electric power," IEEE Trans. Energy Conversion, vol. 14, n4, December 1999, pp. 1417-1423.

[13] T.W.S. Chow et al., "Three phase induction machines asymmetrical faults identification using bispectrum," IEEE Trans. Energy Conversion, vol. 10, $\mathrm{n}^{\circ} 4$, December 1995, pp. 688-693.

[14] S.M. Kay, Modern Spectral Estimation, Prentice-Hall Signal Processing Series, 1988

[15] A.A. Da Silva et al., "Rotating machinery monitoring and diagnosis using short-time Fourier transform and wavelet techniques," Proceedings of the 1997 International Conference on Maintenance and Reliability, Knoxville (USA), vol. 1, pp. 14.01-14.15.

[16] W.J. Wang et al., "Application of wavelets to gearbox vibration signals for fault detection," J. Sound \& Vibration, vol. 192, n5, 1996, pp. $927-$ 939.

[17] A.J.M. Cardoso et al., "Computer-aided detection of airgap eccentricity in operating three-phase induction motors by Park's vector approach," IEEE Trans. Industry Applications, vol. 29, n5, September-October 1993, pp. 897-901

[18] S.M.A. Cruz et al., "Rotor cage fault diagnosis in three-phase induction motors, by extended Park's vector approach," Proceedings of the 1998 International Conference on Electrical Machines, Istanbul (Turkey), vol. 3, pp. 1844-1848

[19] B. Boashash, "Time-frequency signal analysis," in Advances in Spectrum Analysis and Array Processing, S. Haykin Ed., Englewood Cliffs, NJ: Prentice Hall, 1990, pp. 418-517.

[20] B. Yazici et al., "An adaptive statistical time-frequency method for detection of broken bars and bearing faults in motors using stator current," IEEE Trans. Industry Applications, vol. 35, n², March-April 1999, pp. 442-452.

[21] J. Milimonfared et al., "A novel approach for broken-rotor-bar detection in cage induction motors," IEEE Trans. Industry Applications, vol. 35, n5, September-October 1999, pp. 1000-1006. 


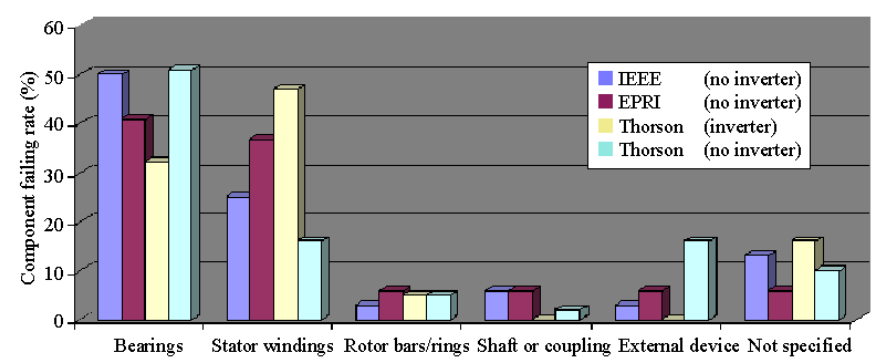

Fig. 1. Induction motor component failing rate versus survey [2]

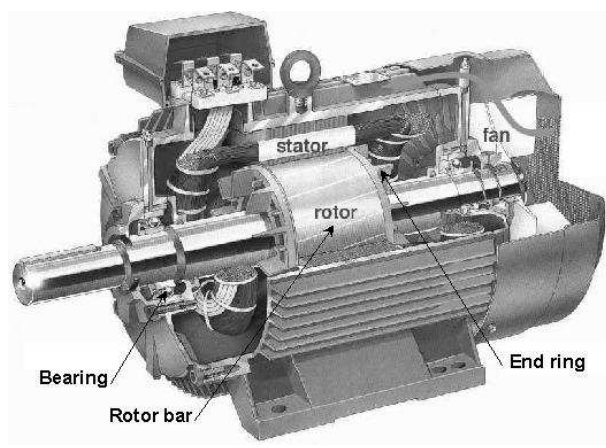

Fig. 2.View of a cage induction motor.
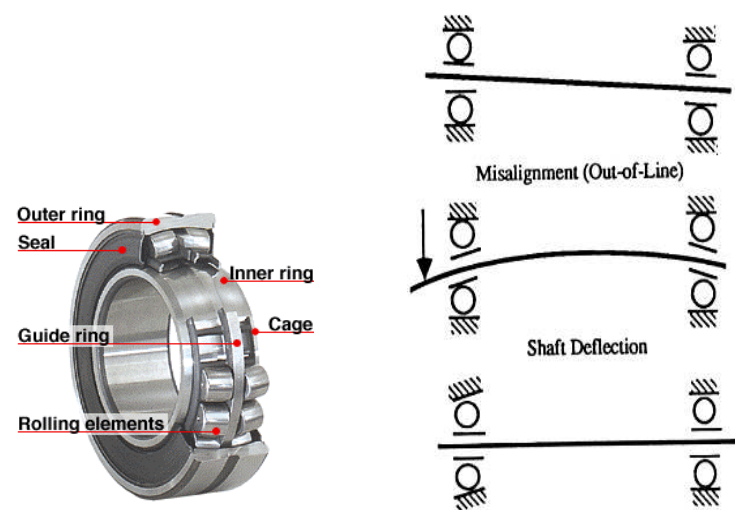

Shaft Deflection

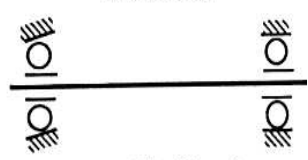

Cocked or Tilted Outer Race

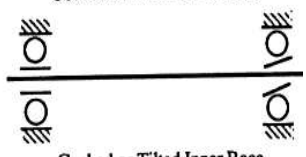

Cocked or Tilted Inner Race

Fig. 3. Four types of rolling-element bearing misalignment.
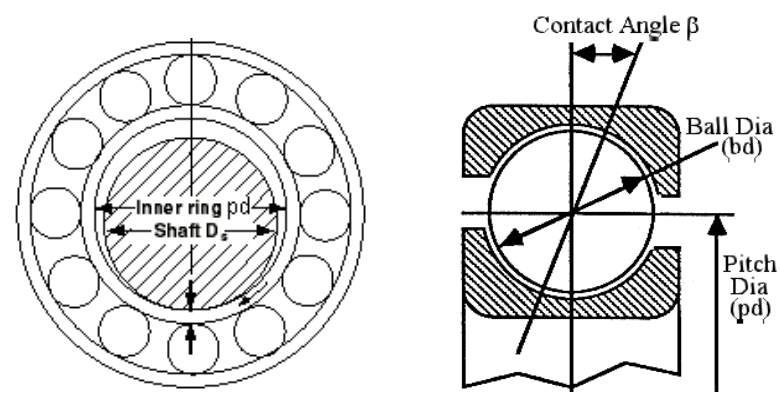

Fig. 4. Ball bearing dimensions.

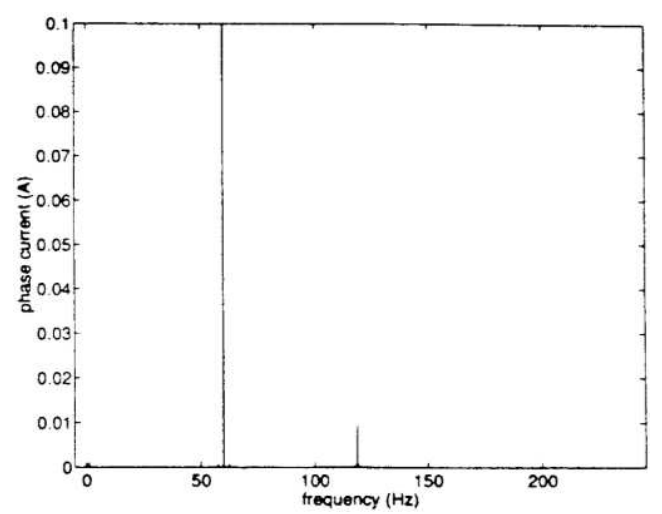

(a) Current spectrum with an eccentric airgap and a constant load torque

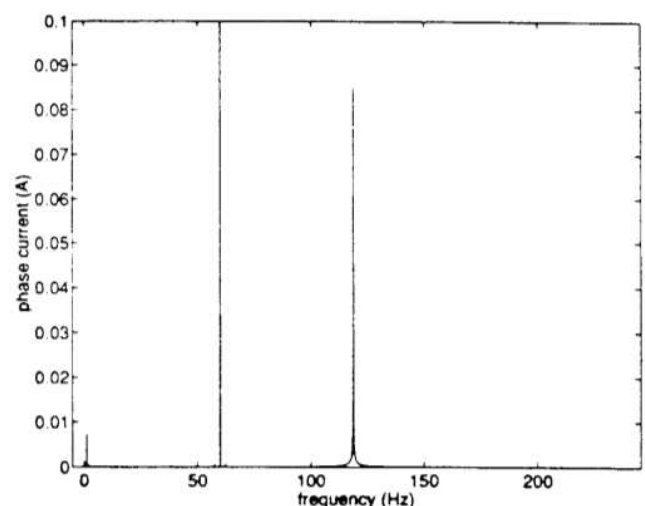

(b) Current spectrum with an eccentric airgap and a load torque oscillation. Fig. 5. Load torque oscillation effect.

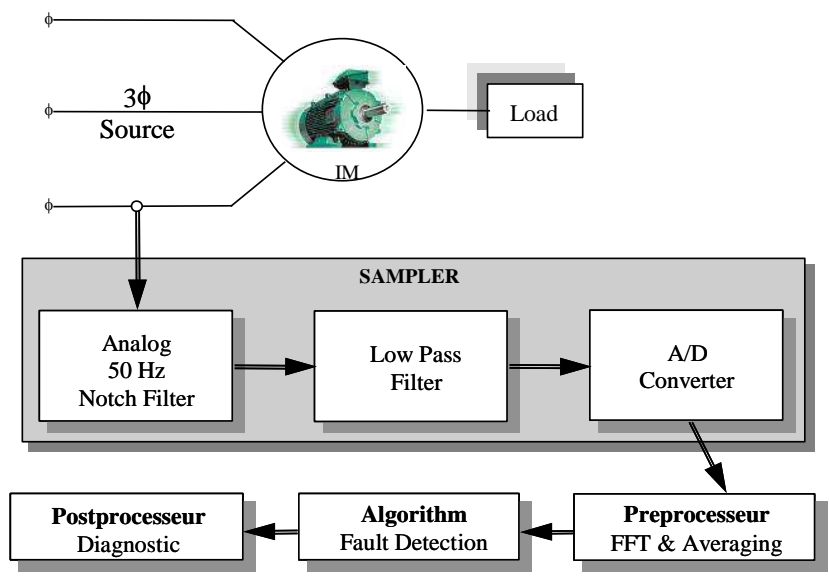

Fig. 6. Single-phase stator current monitoring scheme.

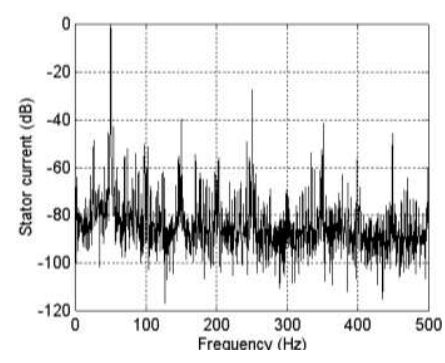

(a)

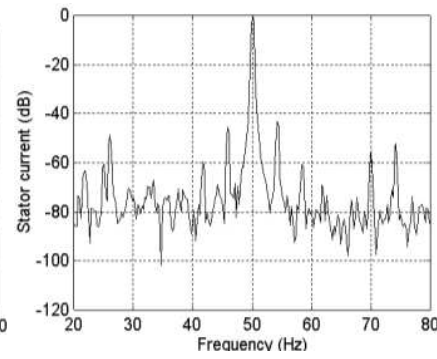

(b) Power spectrum around $50 \mathrm{~Hz}$.
Fig. 7. Stator current power spectra of healthy motor. 


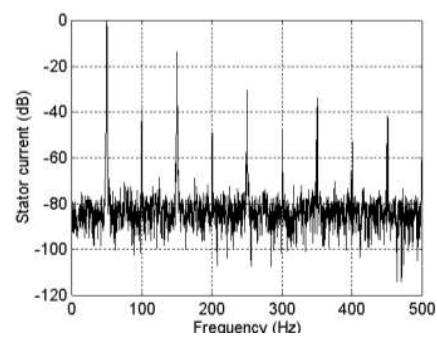

(a) Stator voltage unbalance.

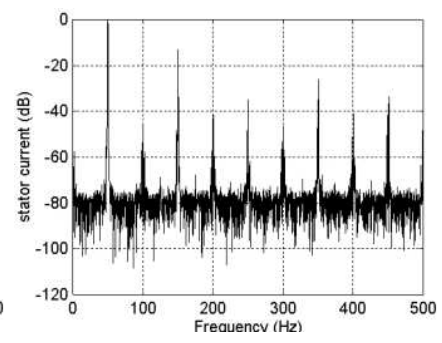

(b) Stator open phase.

Fig. 8. Stator current power spectra of faulty motor.

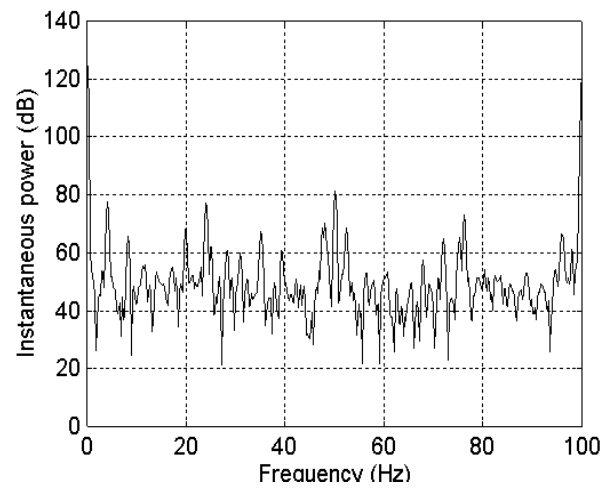

Fig. 9. Power spectrum of the instantaneous power.

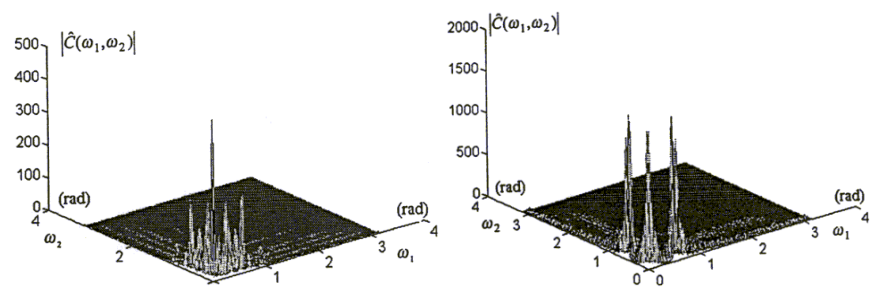

(a) Healthy motor.

(b) Stator winding faults Condition.

Fig. 10. Bispectrum.

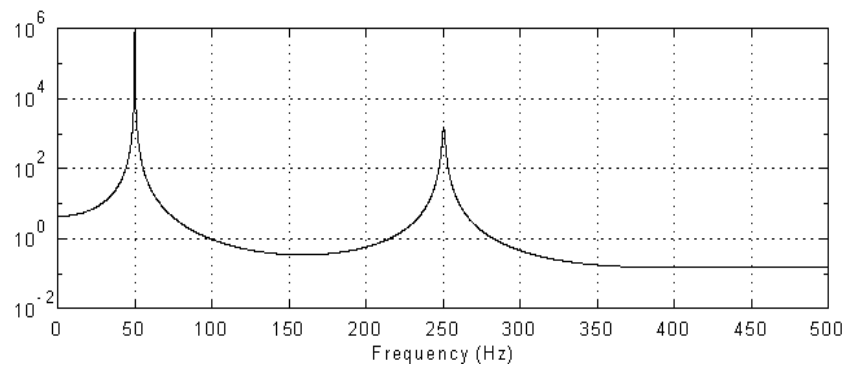

(a) Healthy motor.

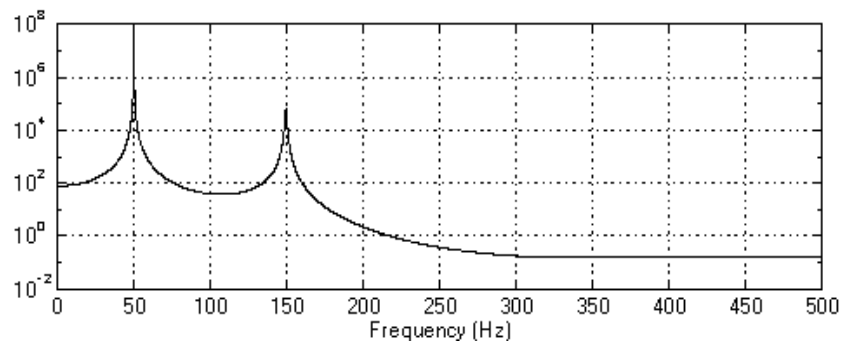

(b) Stator voltage unbalance

Fig. 11. MUSIC frequency estimate.

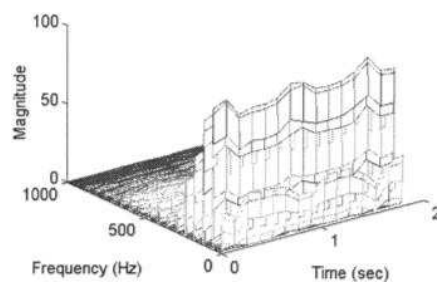

(a) STFT.

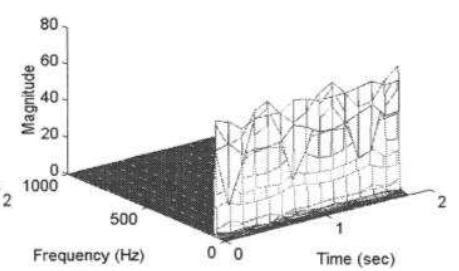

(b) STFT and wavelet technique.
Fig. 12. Misalignment detection.

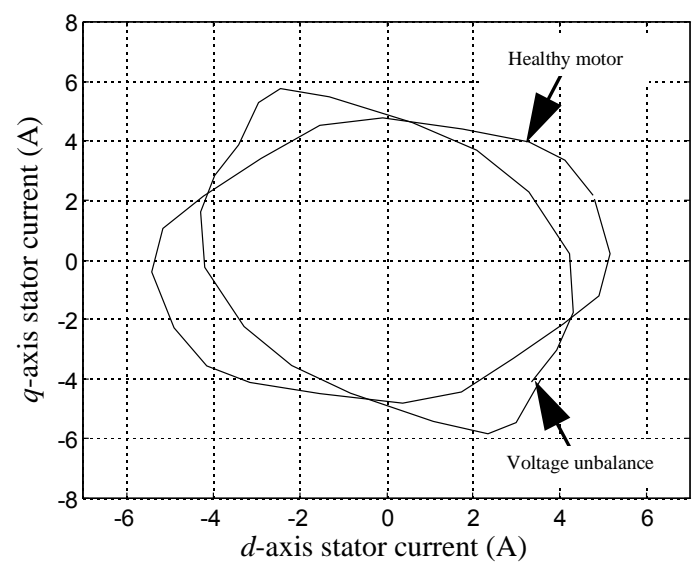

Fig. 13. Stator current Park's vector pattern.

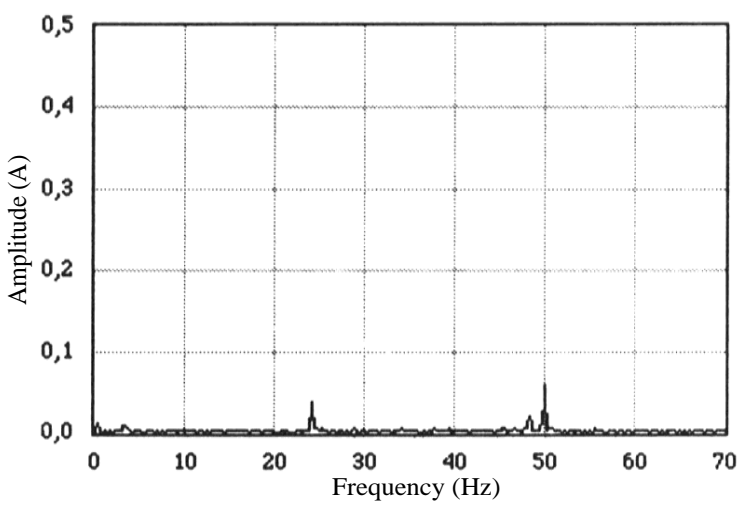

(a) Healthy induction motor.

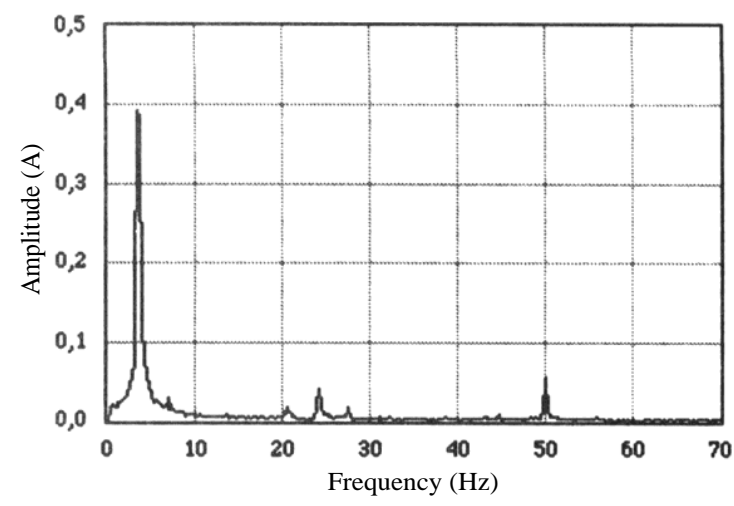

(b) Four contiguous broken rotor bars.

Fig. 14. Spectrum of the stator current Park's vector ac level. 
Training Data

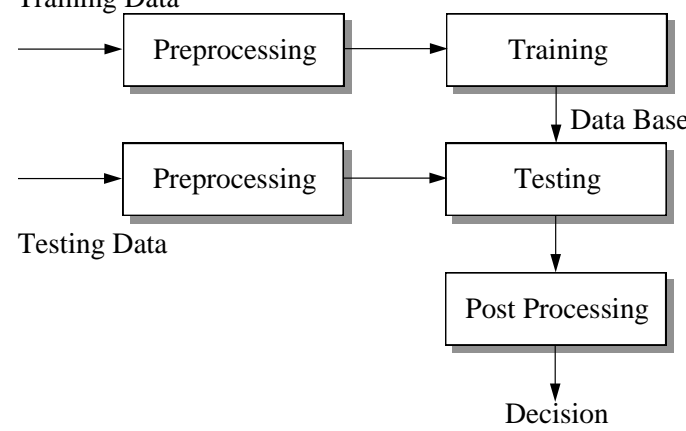

Fig. 15. Block diagram of the adaptive statistical time-frequency fault detection technique.

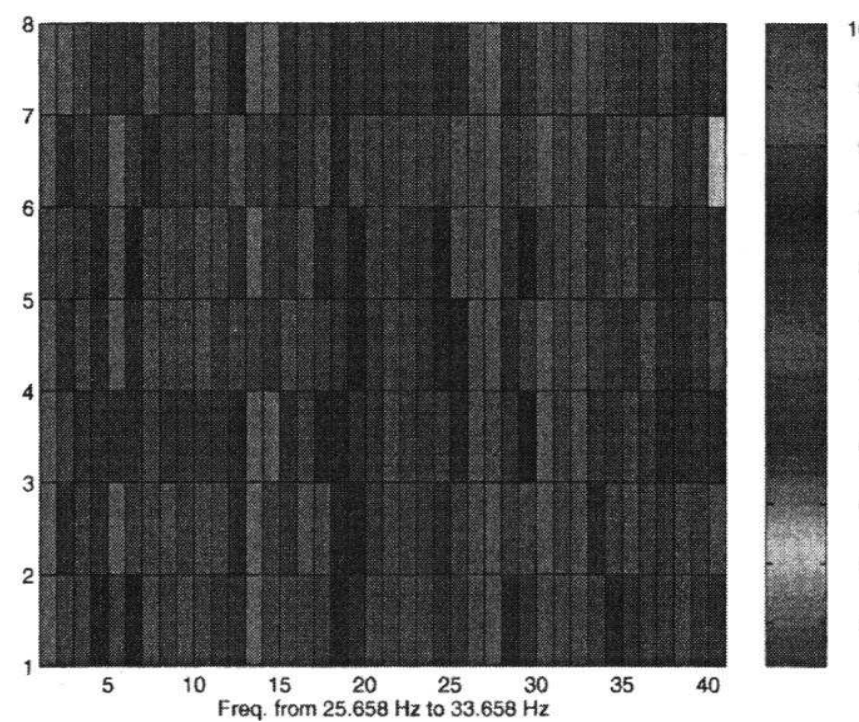

(a) Normal mode.

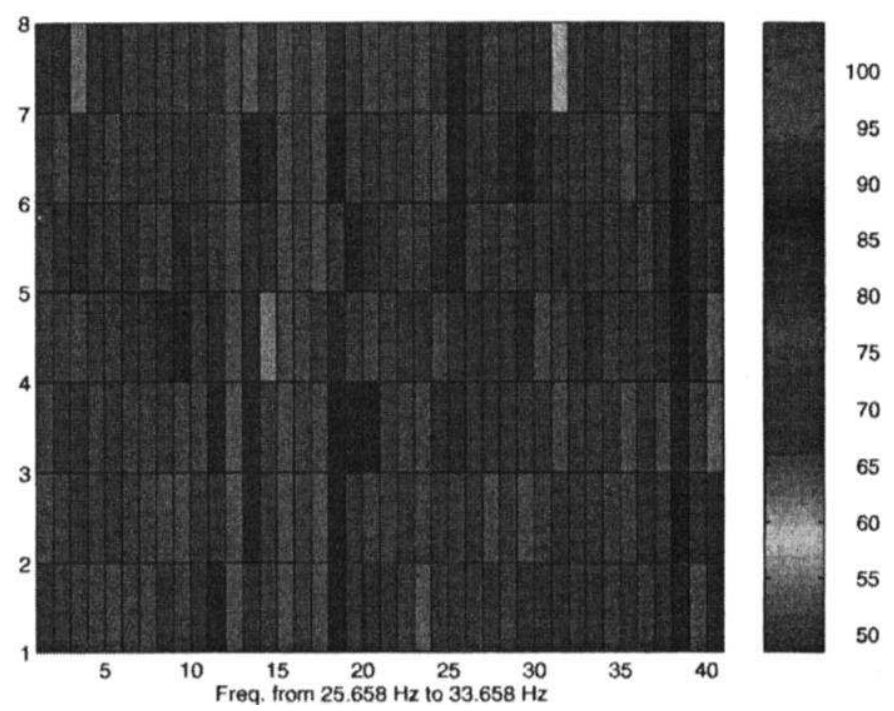

(b) Faulty bearings.

Fig. 16. Time-frequency spectrum of an induction motor.

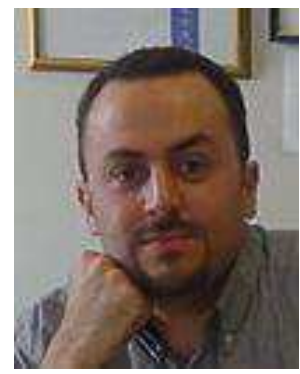

Mohamed El Hachemi BENBOUZID (S'92M'94-SM'98) was born in Batna, Algeria, in 1968. He received the B.Sc. degree in Electrical Engineering, in 1990, from the Electrical Engineering Institute of Batna University, Algeria; the M.Sc. and Ph.D. degrees both in Electrical and Computer Engineering, from the National Polytechnic Institute of Grenoble, France, in 1991 and 1994 respectively.

After graduation, he joined the University of Picardie "Jules Verne", France, where he is an Associate Professor of Electrical and Computer Engineering at the Professional Institute of Amiens. In November 2001, he received the "Habilitation à Diriger des Recherches" degree from the University of Picardie "Jules Verne". His current research interests include electric machines and drives, computational of electromagnetics, and electromechanical actuation, as well as techniques for energy savings.

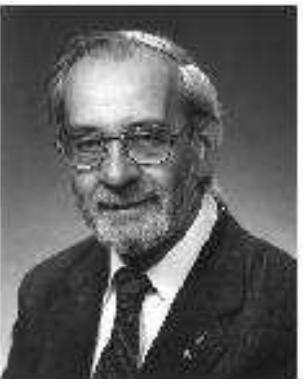

Gerald B. Kliman (S'52-M'55-SM'79F'92) received the S.B., S.M., and Sc.D. degrees from Massachusetts Institute of Technology, Cambridge, in 1955, 1959, and 1965 , respectively.

Following graduation, he was an Assistant Professor of Electrical Engineering at Rensselear Polytechnic Institute, Troy, NY. He then had several assignments in the Transportation Division of General Electric Company, where he worked on adjustablespeed drives, high-speed linear induction motors, and large electromagnetic pumps. He was with Corporate Research and Development, General Electric Company, Schenectady, NY, where he conducts fundamental studies of linear, synchronous, permanent-magnet, and induction motors, advanced drive systems for traction, the development of high-efficiency and high-speed motors, and the application of new developing magnetic and nonmagnetic materials and insulation. A major emphasis has been the development of fault and incipient fault detection techniques for electric motors and drives. He retired from GE in November 2001 and became a Research Professor at the Electrical, Computer \& Systems Engineering department of the Rensselaer Polytechnic Institute, Troy, NY. Prof. Kliman is an Associate Editor of Electric Machines and Power Systems. He is the holder of 45 US patents and the author of numerous publications. 